\title{
Effect of different ligands on the controlled polymerization of monodisperse polystyrene nanospheres by atom transfer radical polymerization in an aqueous emulsion
}

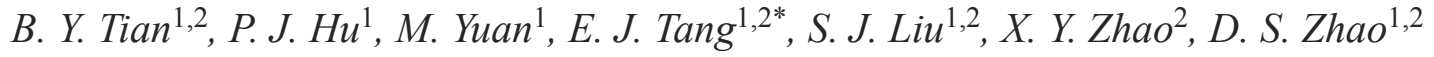 \\ ${ }^{1}$ School of chemical and pharmaceutical engineering, Hebei University of Science and Technology, 050018 Shijiazhuang \\ Hebei, China \\ ${ }^{2}$ Hebei research center of pharmaceutical and chemical engineering, Hebei University of Science and Technology, 050018 \\ Shijiazhuang Hebei, China
}

Received 14 March 2012; accepted in revised form 15 May 2012

\begin{abstract}
Polystyrene nanospheres have been synthesized by atom transfer radical polymerization (ATRP) to control the molecular weight distribution in the aqueous system. The crucial factor in such a system is the ligand that adjusts the solubility of the catalyst in different phases to control the concentration of both the activator and the deactivator in reaction phase. The effect of different ligands including ethylenediamine, 1,10-phenanthroline (phen) and 4,4-dinonyl-2, 2-bipyridyl (dNbpy) on the catalytic solubility in the organic and aqueous phase has been investigated. The molecular weight distribution of polymer obtained in this way was analyzed by gel permeation chromatography (GPC). It showed that the obtained polymer particles presented a broad molecular weight distribution (polydispersity index 1.78) with ethylenediamine as the ligand, but the polymerization rate was high and conversion reached $96.8 \%$. The molecular weight distribution of polystyrene was narrowest with dNbpy as ligand, but the conversion was lowest and only achieved to 69\%. Possible reasons were the influence of the structure of three different ligands on the control of ATRP reaction. SEM and GPC indicated that the polystyrene nanospheres presented regular sphere with a diameter of about $120 \mathrm{~nm}$ and uniform molecular weight distribution, which possessed a significant potentials in drug carrier field.
\end{abstract}

Keywords: polymer synthesis, ATRP, aqueous emulsion polymerization, polystyrene nanosphere, ligand

\section{Introduction}

Monodisperse polymer nanospheres have found a wide variety of applications in coating, instrument calibration, chromatography and biomedical treatment etc [1]. However, polymer materials produced by traditional radical polymerization have a broad molecular weight distribution. Many applications require particles consisting of a pre-defined molecular weight and a narrow molecular weight distribution [2]. Control over the polymer molecular weight and its distribution during polymerization has long been a challenge in polymer material research, especially in the applications for medicine release material and as biotechnology materials [3, 4]. The advent of atom transfer radical polymerization (ATRP) provides a new way to synthesize polymers with controlled molecular weight [5-7]. Numerous well-defined (co)polymers with the desired molecular weight and low polydispersity index $(\mathrm{PDI}<1.5)$ $[8,9],($ co)polymers with complex architectures [10-13], functional polymers and hybrid materials have been prepared by the ATRP technique [1416]. Atom transfer radical polymerization (ATRP) also remains one of the most powerful, versatile,

\footnotetext{
${ }^{*}$ Corresponding author, e-mail: ejtang@sohu.com
}

(c) BME-PT 
simplest, and least expensive polymerization techniques [17]. Not only does this feature offer ability to tailor the polymer coatings to possess a variety of compositions and functionality, but this feature may be important in biomedical applications to modify a biological polymer specifically for cellular interactions $[18,19]$. The basis of the ATRP technique is the reversible transfer of a halogen atom from a polymeric alkyl halide $(\mathrm{R}-\mathrm{X})$ to a transition metal complex (LMtn), generating an organic radical and a transition metal complex (LMtn+1X) with a higher oxidation state [20]. To establish the equilibrium between LMtn and $\mathrm{LMtn}+1 \mathrm{X}$ so that it is strongly shifted toward the LMtn complex, many factors should be taken into consideration, involving the monomer, initiator with a transferable halogen, catalyst (composed of a transition metal species with any suitable ligand), solvent and temperature [21].

Over the past few years, extensive studies on ATRP have mainly focused on homogeneous bulk or solution systems to obtain a variety of well-defined (co)polymers with controlled molecular weights. Its use has been demonstrated for the synthesis of a series of functional monomers such as (meth)acrylate, (meth)acrylamide and (meth)acrylic acids, giving the target polymers better control of the molecular weight and distribution [22-25]. Currently, in order to meet the requirements for environmentally benign technology and the development of sustainable chemistry, some new strategies are beginning to be pursued. The major approach is based on using water as the solvent, both from an environmental view and safety related reasons [26, 27]. In aqueous dispersed media, such as an emulsion or suspension, the polymerization is able to effectively transfer heat from exothermic polymerization processes and allows a dramatic increase of the polymerization rate [28]. The polymer nanospheres produced in this way can be used directly in drug delivery, microencapsulation and many other applications [29]. However, unlike bulk/solution ATRP, to maintain the 'living' character of the polymerization in a stable emulsion, many factors need to be considered. For instance, the choice of an appropriate surfactant, the solubility of the initiator and the radical trapping agent in both the organic and aqueous phases, avoidance of any potential side reactions caused by water and a high reaction tempera- ture, all require attention. Among these, the choice of ligand is a crucial factor that adjusts the catalytic solubility in the organic and aqueous phases and has a tremendous impact on the controlled polymerization. It should be noted that a further requirement of the ligand (such as dNbpy) for aqueous dispersion is that it must form soluble catalyst complexes with the chosen monomer. The ligand can then improve the retention of the catalyst in the particle phase where polymerization takes place and minimize partitioning into the aqueous phase. However, it is well known that even with a hydrophobic ligand, not all of the catalyst complex can be prevented from partitioning into the aqueous phase [28].

The object of this work was to investigate the ability to control the molecular weight and latex stability of polystyrene nanospheres using ATRP in an aqueous emulsion system. The ligand adjusts the solubility of the catalyst in the different phases to control the concentration of both the activator and the deactivator in the reaction phase. The selection of the ligand becomes a key for controlling the reaction and molecular weight in the aqueous system. Ethylenediamine, phen and dNbpy were used as ligands with various experimental conditions. The influence of the ligands on the conversion and molecular weight distributions is then discussed. The reason for the different results obtained is analysed primarily by consideration of the solubility of the metal-ligand complexes in the organic phase and the structure of ligand.

\section{Experimental}

\subsection{Materials}

Commercially available styrene (St) was purchased from Beijing Dong fang Chemical Co. Ltd. (China). The St was distilled under reduced pressure and then kept refrigerated until used. Nonyl phenyl ether polyoxyethylene (10) (OP-10, AR) and sodium dodecyl sulfate (SDS) were obtained from the Beijing Chemical Plant (Beijing, China) and used without further purification. Copper chloride $(\mathrm{CuCl}$, $\mathrm{AR})$, carbon tetrachloride $\left(\mathrm{CCl}_{4}, \mathrm{AR}\right)$, hexadecane (HD, AR) and polyoxyethylene sorbitan monoleate (TW-80, AR) were supplied by Tianjin Chemistry Reagent Co, Ltd, China. 1, 10-phenanthroline (phen, analytically pure) and ethylenediamine (analytically pure) were supplied by the Tianjin Research 
Institute of Synthetic Material (China) and used without further purification. 4, 4-dinonyl-2, 2bipyridyl (dNbpy), analytically pure, was purchased from the Hangzhou Chemistry Co. Ltd. (China). Deionized water was used for all polymerization and characterization processes.

\subsection{Polymerization procedure}

The polymerization was conducted in a flask fitted with a mechanical stirrer, nitrogen inlet and condenser. Copper(I) chloride (0.15 g) and different amounts of ligand were directly dispersed into monomers. The monomer mixture was added to an aqueous solution of the surfactant with hexadecane and then dispersed for $20 \mathrm{~min}(450 \mathrm{~W})$ using an ultrasonic instrument (KQ-2300, $150 \mathrm{~W}$, China) at room temperature. Afterwards, the mixture was added to a flask with constant stirring under high purity nitrogen $\left(\mathrm{N}_{2} 99.999 \%\right)$. The reactor was immersed in a thermostated water bath to maintain a constant temperature. A certain amount of $\mathrm{CCl}_{4}$ was added to the reaction system held at the specified temperature $\left(80^{\circ} \mathrm{C}\right)$ and the time noted. The polymerization reaction was carried out at constant temperature for $8 \mathrm{~h}$ to obtain the latex nanospheres.

\subsection{Characterization}

The monomer conversion was determined by a conventional gravimetric method. The molecular weight and the distribution of the polymer were characterized by gel permeation chromatography (GPC, HLC-8220) on a system equipped with a SHIMADZU (LC-10ADVP) pump and a RID-10A detector, with THF as the eluent and a flow rate of $1 \mathrm{~mL} / \mathrm{min}$. Narrow-standard polystyrene was used to generate a universal calibration curve. The partitioning of the complexes which were formed by the $\mathrm{CuCl}$ and different ligands were determined by UV-VIS spectrophotometry [29]. The latex nanosphere diameter was determined using a dynamic light scattering particle size analyzer (DLS BI90Plus, Brookhaven Instruments Co., USA). The dispersion morphology of the particles in the latex system was observed using transmission electron microscopy (TEM 100CX-II, Jeol Co., Japan).

\section{Results and discussion \\ 3.1. The mechanism of synthesizing polystyrene nanospheres with ATRP in emulsion system}

For this part of the investigation, a certain amount of emulsifier TW-80 was added to the reaction system to emulsify the organic monomer using the ultrasonic emulsification instrument in an aqueous system [30]. Subsequently, a large quantity of miniemulsion droplets was obtained and the ATRP reaction was carried out in the monomer droplets to obtain the nanosphere materials. The mechanism for the synthesis of the polystyrene latex nanospheres is shown in Figure 1. At the beginning of polymerization, copper(I) chloride and ligand were dispersed into monomers and the mixture was dispersed ultrasonically. The ligand can increase the solubility of the catalyst in the organic phase, so that the complex is diffused into the monomer droplets at the beginning of the polymerization. A certain amount of initiator $\mathrm{CCl}_{4}$ was then added to the reaction system. In the initiation step, the transition metal complex abstracts the halogen from the organic halides, creating a radical that adds to the monomer; the resulting radical species then propagates further. As the radical propagation reaction takes place, it is rapidly deactivated by a reaction with the oxidized transition-metal/ligand complex, regenerating a halogen-terminated polymeric chain [31]. Through the equilibrium between the activator and the deactivator in the reaction droplets, polymer particles with a narrow molecular weight distribution were obtained using this ATRP method.

For this system, the transition-metal/ligand complex is located in the organic monomer phase (styrene) where the ATRP reaction takes place. In

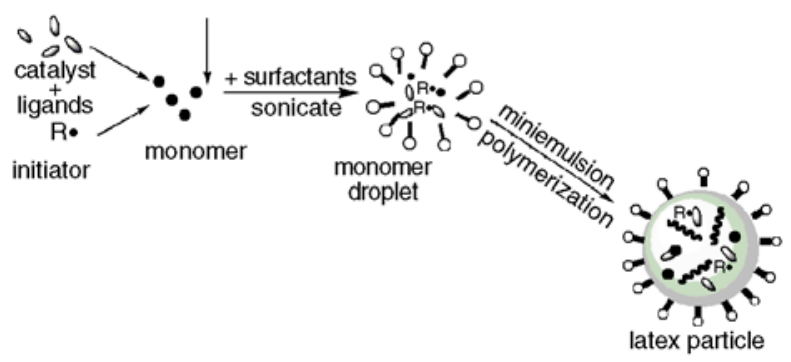

Figure 1. The mechanism of synthesizing polystyrene nanospheres by ATRP in miniemulsion droplets 
addition, it may be located in aqueous phase, depending on the solubility of the ligand. If the majority of the complex remains in the organic phase, the control polymerization would be easily carried out. If not, the transition metal complex can diffuse into the aqueous phase and the radical species may be difficult to deactivate. The trend of radical propagation polymerization would play a major role. As a consequence, the controlled polymerization could not be completed perfectly and the molecular weight distribution of the polymer obtained would be broadened.

\subsection{Solubility of the different catalytic system in organic and aqueous phase}

The partition of the complexes which formed by $\mathrm{CuCl}$ and different ligands were determined by UVVIS spectrophotometry [29]. Figure 2 shows the UV-VIS absorption spectrum curve of complex which formed by $\mathrm{CuCl} /$ ethylenediamine. A comparison of the absorption spectra of the complex in the organic phase and aqueous phase before and after mixing with water revealed a remarkable change at the relative intensity of the peaks around $580 \mathrm{~nm}$. The resulting complex had a very low solubility in organic phase before mixing with water, but stronger characteristic absorption peak emerged in the aqueous phase after mixing with water. Figure 3 shows that the complex which formed with $\mathrm{CuCl}$ and phen emerged stronger characteristic absorption peak around $660 \mathrm{~nm}$ before mixed with water, and the absorption peak around $660 \mathrm{~nm}$ was weakened in the organic phase after mixing with water. Figure 4 shows that the complex $(\mathrm{CuCl} / \mathrm{dNbpy})$ exhibited

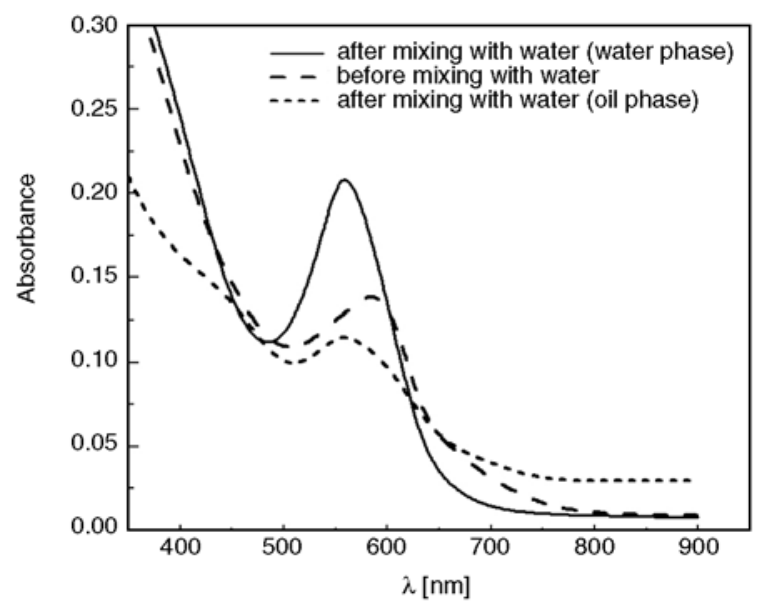

Figure 2. The absorbance of complex which formed $\mathrm{CuCl} /$ ethylenediamine. Temperature: $25^{\circ} \mathrm{C}$; $[\mathrm{CuCl}] /[$ ethylenediamine]:1/2; the oil phase was styrene.

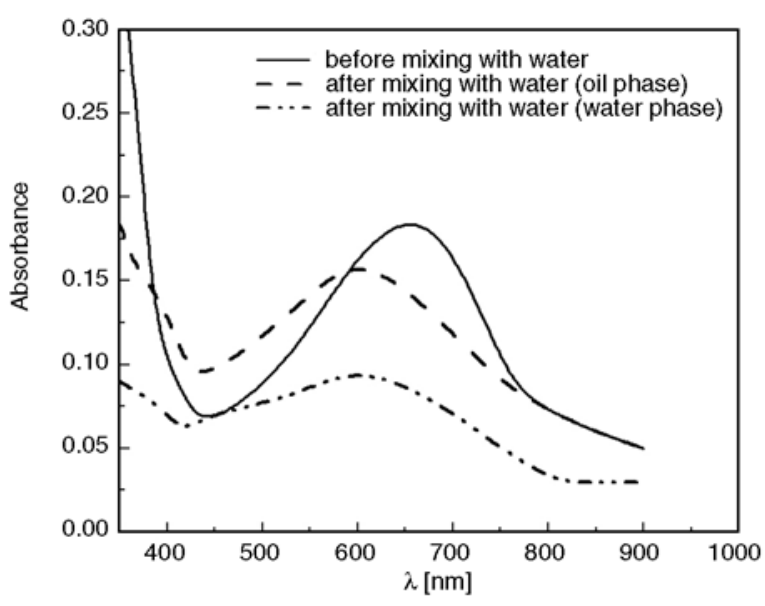

Figure 3. The absorbance of complex which formed $\mathrm{CuCl} /$ phen. Temperature: $25^{\circ} \mathrm{C} ;[\mathrm{CuCl}] /[\mathrm{phen}]: 1 / 2$; the oil phase was styrene.

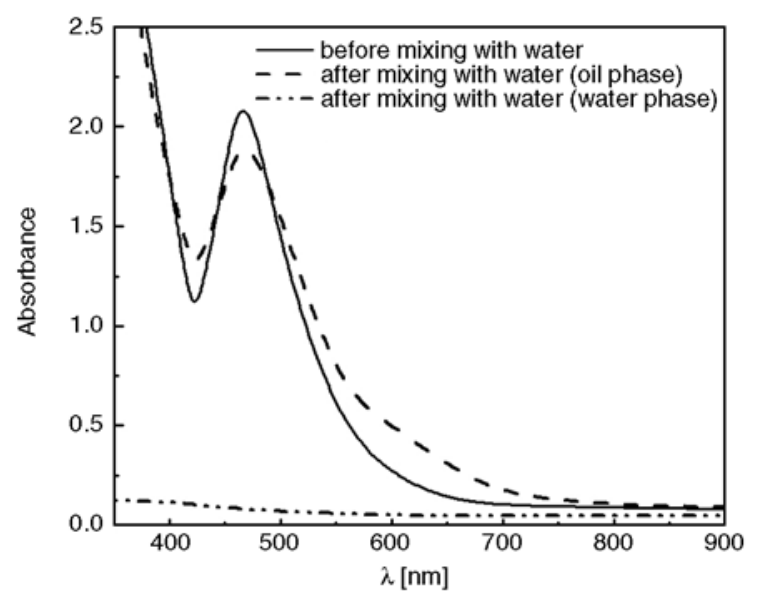

Figure 4. The absorbance of complex which formed $\mathrm{CuCl} /$ dNbpy. Temperature: $25^{\circ} \mathrm{C}$; $[\mathrm{CuCl}] /[\mathrm{dNbpy}]: 1 / 2$; the oil phase was styrene.

stronger characteristic absorption peak around 460 $\mathrm{nm}$ in the organic phase.

By comparing the three different metal complexes, the results indicated that $\mathrm{CuCl} /$ ethylenediamine was highly soluble in water phase and a lot of complexes were easily migrated to the aqueous phase. However, the complex of $\mathrm{CuCl} / \mathrm{dNbpy}$ exhibited stronger characteristic absorption peak in the visible range. That is to say, the complexes had a stronger solubility in organic phase and the majority of the complex remains in the organic phase after mixing with water. The solubility of $\mathrm{CuCl} /$ phen in organic phase was between the two complexes mentioned above.

In ATRP, equilibrium switching between the $n$ and $n+1$ oxidation states was achieved by using a metal complex [32]. Since the polymer chains grow in the organic phase, the first requirement for control of 
the polymerization is to have a sufficient concentration of both the activator and the deactivator in the organic phase where reaction is to take place. The ligand increases the solubility of the catalyst in the organic phase. Therefore the choice of the proper ligand becomes crucial.

\subsection{Influence of different kinds of ligands on the control of the ATRP reaction}

The key to controlling the radical polymerization is to maintain a rapid equilibrium between the growing radicals and the dormant species. To facilitate a successful ATRP, it is essential to have both a radical activator and deactivator available in the organic phase where the polymerization takes place [33]. One role of the ligand is to adjust the partitioning behavior of the metal complex between the oil phase and the aqueous phase. Thus, the selection of a suitable ligand becomes essential.

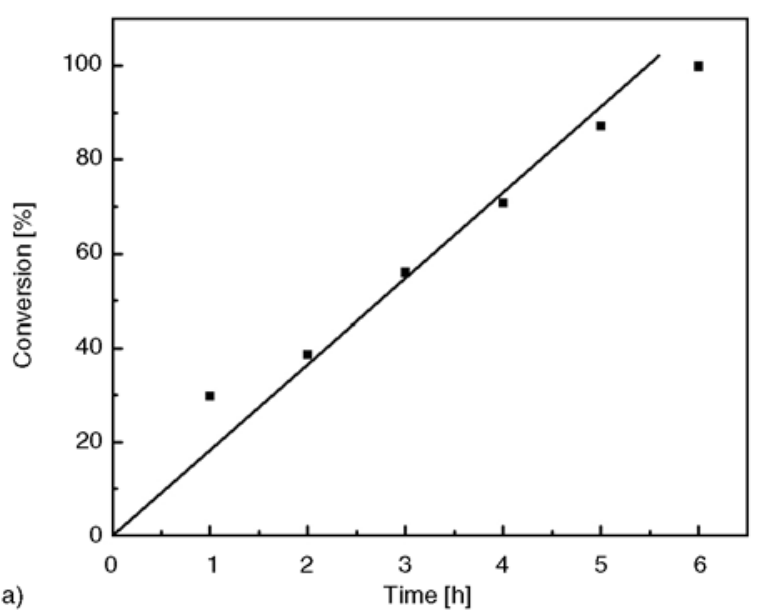

In this system, $\mathrm{CuCl}$ was added to the ATRP system to facilitate the establishment of the equilibrium between the radical and dormant species. The relationship of the molecular weight versus conversion and that of conversion versus time with ethylenediamine as the ligand are shown in Figures $5 \mathrm{a}$ and $5 \mathrm{~b}$. It can be seen that the polymer finally obtained had a very broad molecular weight distribution with a polydispersity index of 1.78. A long tail was found in the GPC curves with a conversion of $96.8 \%$. In contrast, experiments with phen and dNbpy as the ligand system were also carried out. Figures 6a and $6 \mathrm{~b}$ show the relationship of conversion versus time and the relationship of molecular weight versus conversion with phen as the ligand. The results revealed that the conversion of styrene gradually increased with the polymerization time. The polymer obtained with phen as ligand had a narrow molecular weight distribution (PDI:1.65) and lat-

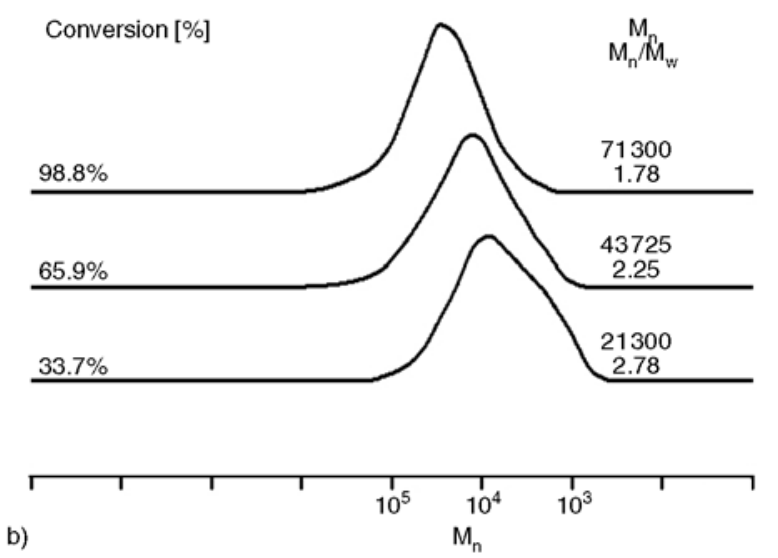

Figure 5. The relationship of conversion versus time (a) and that of molecular weight versus conversion with ethylenediamine as ligand (b)
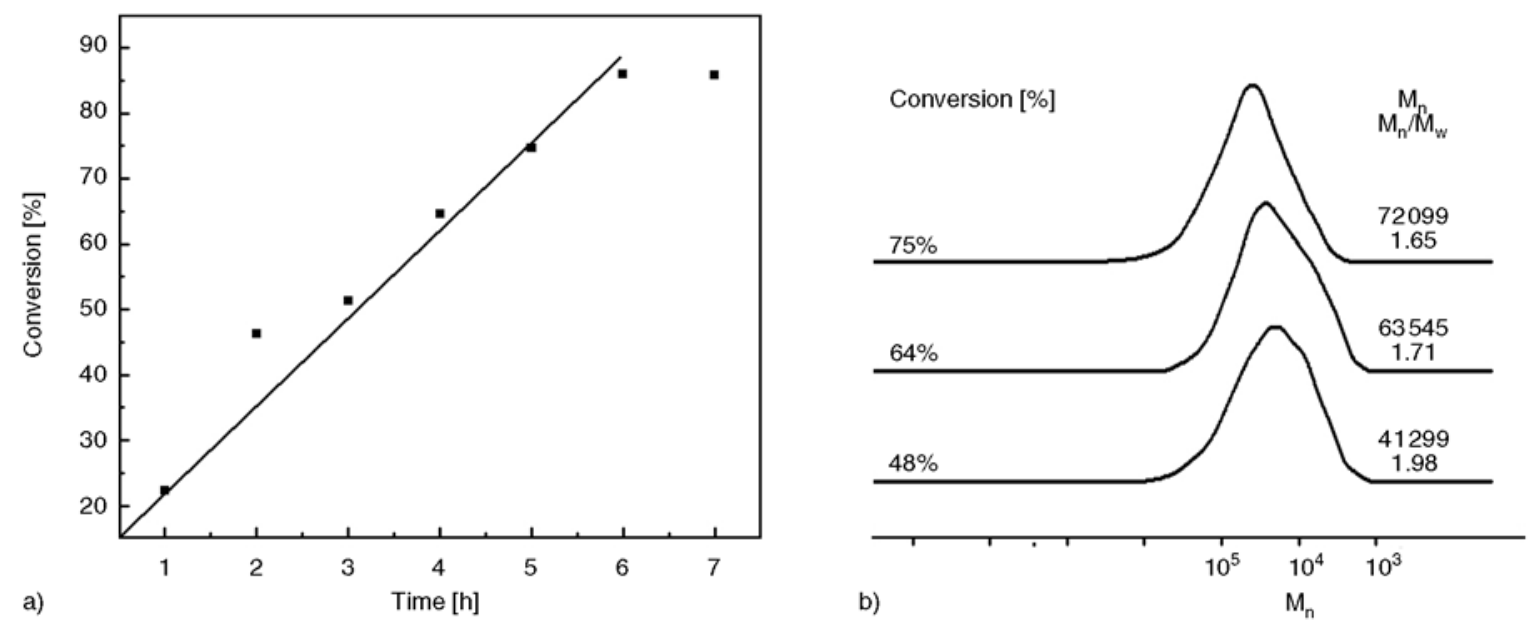

Figure 6. The relationship of conversion versus time (a) and that of molecular weight versus conversion with phen as ligand (b) 

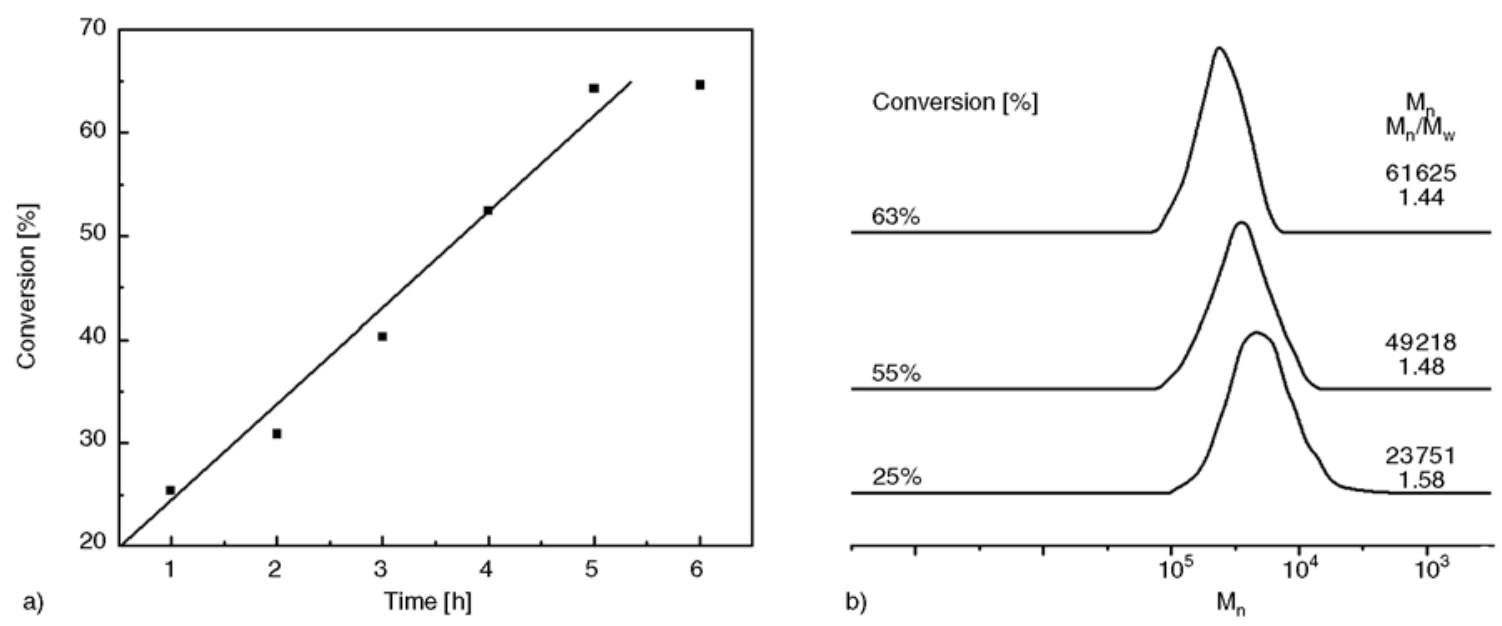

Figure 7. The relationship of conversion versus time (a) and that of molecular weight versus conversion with dNbpy as ligand (b)

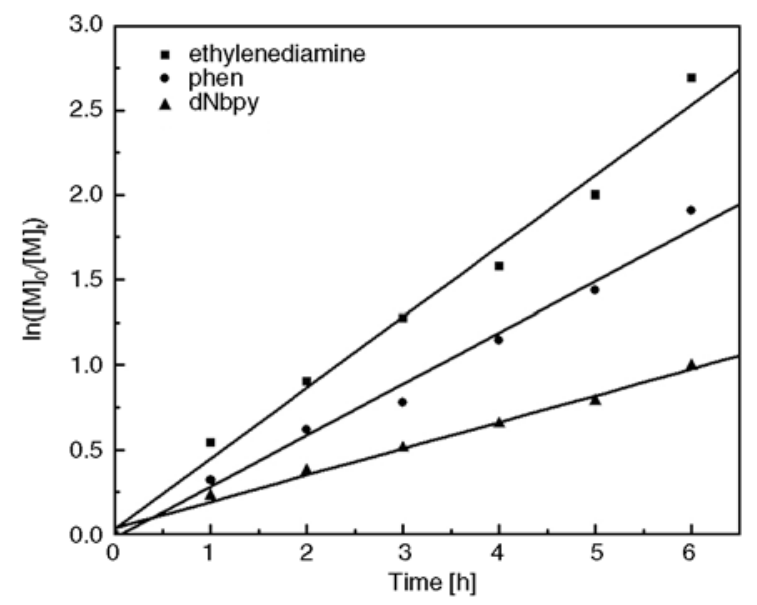

Figure 8. The relationship of $\ln \left([M]_{0} /[M]_{\mathrm{t}}\right)$ versus time for the emulsion ATRP of St with three different ligand(ethylenediamine, phen, dNbpy)

eral shift with increasing of conversion towards higher molecular weight. Figures $7 \mathrm{a}$ and $7 \mathrm{~b}$ show the relationship of conversion versus time and the relationship of molecular weight versus conversion with dNbpy as ligand. The molecular weight distribution of polystyrene was the narrowest (PDI:1.44) of the three samples, but the conversion was also lowest, only reaching $69 \%$. Figure 8 shows the relationship of $\ln \left([M]_{0} /[M]_{\mathrm{t}}\right)$ versus time of the emulsion ATRP of St with the three different ligands (ethylenediamine, phen, dNbpy). It shows that the polymerization rate obeyed almost first order kinetics [34]. The polymerization rate with the $\mathrm{CuCl} /$ ethylenediamine system was faster than either the $\mathrm{CuCl} / \mathrm{dNbpy}$ or $\mathrm{CuCl} /$ phen systems.

From the above results we found that phen and dNbpy had higher solubility in the organic phase, especially dNbpy. The hydrophobic ligand can increase the solubility of the catalyst in the organic phase where the polymerization takes place. So the most efficiently controlled polymerization (giving a polydispersity below 1.50 ) was produced using the $\mathrm{CuCl} / \mathrm{dNbpy}$ complex which facilitated a balance between the activation and deactivation processes in the reaction phase. dNbpy has stronger solubility in the organic phase, so it was employed effectively as a ligand for the ATRP in the emulsion and miniemulsion systems [35]. However, the catalytic activity of the copper complex with dNbpy is rather low and requires a high polymerization temperature, which reduces the stability of the monomer droplets/growing particles and leads to lower conversion during the polymerization.

The reason is possibly due to the different structures of the ligands. It can be found from the structure of the ethylenediamine ligand that the lower steric hindrance around the nitrogen atom was conducive to form the living radical more quickly and so increased the polymerization rate. The above results therefore indicated that $\mathrm{CuCl} /$ ethylenediamine was highly soluble in water and a large quantity of the complexes easily migrated to the aqueous phase. As a result, the particles produced can undergo an uncontrolled conventional free radical polymerization due to the absence of the copper complex as deactivator/activator. With the long alkyl substituent of dNbpy as ligand, the steric hindrance around the nitrogen atoms was significant. To a certain extent, large steric hindrance hindered the formation of a living radical. At the same time the copper complex 
with dNbpy was rather unstable, which decreased the activity of the catalyst. In order to increase the catalytic activity, high polymerization temperature was required, but high temperature reduces the stability of the monomer droplets/growing particles during the polymerization.

In addition, the good oil-solubility of the ligand played a beneficial role for controlling the reaction. Therefore, the experiments demonstrated that the effect of ATRP on the controllability not only depended on the solubility of the catalyst complex in the organic phase, but also depended on its ability for radical trapping.

\subsection{The selection of surfactant in emulsion of ATRP}

The influence of latex stability with different types emulsifiers on the reaction system was studied with dNbpy as ligand (Table 1). It appeared that the stability of system with SDS as emulsifier was poor and the polymer presented a broad molecular weight distribution. The ionic surfactants appeared to be not suitable for the emulsion ATRP [36]. The possible reason was that the system had a lot of hydrophilic groups $-\mathrm{SO}_{4} \mathrm{Na}$, which finally led to the system instability. Nonionic surfactant, however, was good candidates for emulsion ATRP. But OP-10 did not stabilize the system and the latex particles were coagulated after $2 \mathrm{~h}$ from the beginning of polymerization. Among the surfactants in this work, the nonionic Tween 80 presented a perfect result. It obtained a stable reaction system and showed a good livingness for the conversion and control molecular weight of polystyrene nanosphere. Therefore, Tween 80 was employed as emulsifier in this study. One of the major challenges facing emulsionbased ATRP was very limited range of suitable surfactant. The latex stability was a real problem in controlled/living radical polymerization. Therefore, the choice of emulsifier became very essential.

Table 1. Results of the effects of surfactant types on latex nanospheres by ATRP

\begin{tabular}{|l|c|c|c|l|}
\hline $\begin{array}{c}\text { Emulsifier } \\
\text { type }\end{array}$ & $\begin{array}{c}\text { Conversion } \\
{[\mathbf{\%}]}\end{array}$ & $\mathbf{M}_{\mathbf{w}} / \mathbf{M}_{\mathbf{n}}$ & $\begin{array}{c}\text { Diameter } \\
{[\mathbf{n m}]}\end{array}$ & Stability \\
\hline SDS & 8.43 & 4.31 & - & unstable \\
\hline OP-10 & 26.60 & 1.76 & 150 & unstable \\
\hline TW-80 & 97.75 & 1.44 & 120 & stable \\
\hline
\end{tabular}

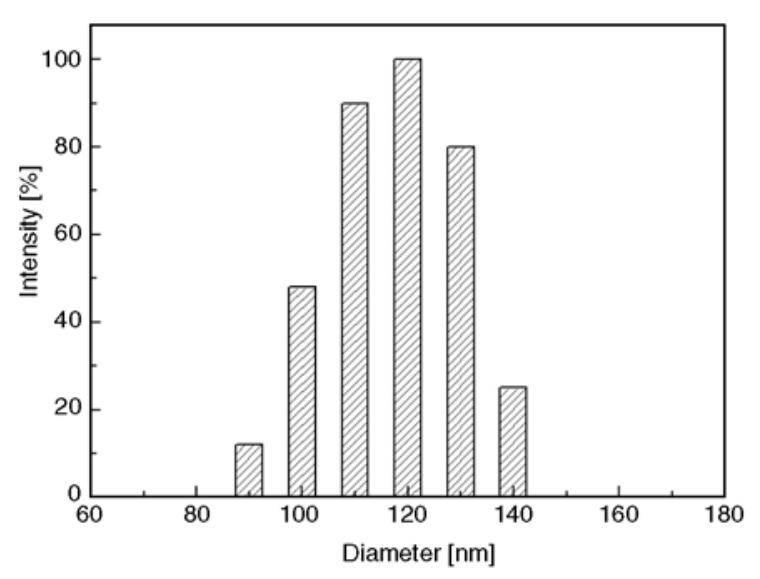

Figure 9. The size distribution of the PSt latex nanospheres produced by ATRP

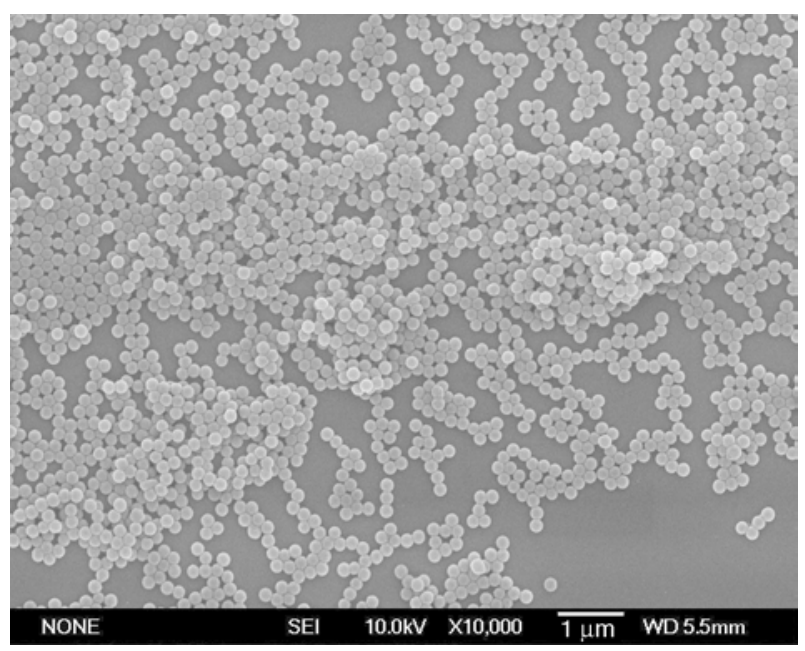

Figure 10. SEM of the PSt latex nanospheres produced by ATRP in emulsion system

Figure 9 shows the size distribution of polystyrene nanosphere by the method of emulsion ATRP with Tween 80 as surfactant. The polystyrene latex nanospheres obtained had a diameter of $120 \mathrm{~nm}$ with a narrow size distribution. The morphology of polymer latex nanosphere was observed by scaning electron microscopy (SEM), as shown in Figure 10. It appeared that the polystyrene latex nanosphere was uniform spherical with a diameter of about $120 \mathrm{~nm}$. The most important predominance was that the polymer particle possessed a narrow molecular weight distribution. In other words, the obtained polymer nanospheres hold a symmetrical configuration and uniform size molecular weight. The material of latex nanosphere produced is very significant in drug targeting carrier systems, the target-selective delivery and release of loaded drugs and other many application fields. 


\section{Conclusions}

The effect of different ligands including ethylenediamine, 1,10-phenanthroline (phen) and 4,4dinonyl-2,2-bipyridyl (dNbpy) on the controlled polymerization of monodisperse polystyrene nanospheres was investigated. Using oil-soluble of ligand (dNbpy), the corresponding polydispersity of polystyrene was 1.44 , but the conversion was at around $69 \%$. The obtained polymer using ethylenediamine as ligand presented a broad molecular weight distribution (polydispersity index 1.78) but the polymerization rate was high and conversion reached to $96.8 \%$. $\mathrm{CuCl} /$ ethylenediamine was highly soluble in water. The metal complexes were easily migrated to the aqueous phase and led to an uncontrolled polymerization reaction, whereas the polymerization rate with the $\mathrm{CuCl}$ /ethylenediamine system was faster than that with the $\mathrm{CuCl} / \mathrm{dNbpy}$ or $\mathrm{CuCl} /$ phen system. The controllability of polymerization reaction depended on the solubility of metal complexes in organic phase, but the structure of ligand and the steric hindrance also played a key role in this system. With dNbpy or phen as ligands the steric hindrance around nitrogen atoms was remarkable. To a certain extent, large steric hindrance hindered the formation of living radical, at the same time the complex with $\mathrm{CuCl}$ was instable, which decreased the catalytic activity of the catalyst. Tween 80 presented the best results of latex nanosphere stability in the system. SEM showed the polystyrene latex nanospheres were uniform spherical with a diameter of about $120 \mathrm{~nm}$. The material of latex nanosphere presented a significant potential in drug targeting carrier field.

\section{Acknowledgements}

The authors are grateful to the financial supports by the Natural Science Foundation of Hebei Province, China (E2007000629), Science and Technology Supported Item of Hebei Province, China (09215109D).

\section{References}

[1] Dai Q., Wu D., Zhang Z., Ye Q.: Preparation of monodisperse poly(methyl methacrylate) particles by radiation-induced dispersion polymerization using vinyl terminus polysiloxane macromonomer as a polymerizable stabilizer. Polymer, 44, 73-77 (2003).

DOI: $10.1016 / \mathrm{S} 0032-3861(02) 00728-0$
[2] Song J-S., Winnik M. A.: Monodisperse, micrometersized low molar mass polystyrene particles by twostage dispersion polymerization. Polymer, 47, 45574563 (2006). DOI: 10.1016/j.polymer.2006.04.025

[3] Eslami H., Zhu S. P.: Emulsion atom transfer radical polymerization of 2-ethylhexyl methacrylate. Polymer, 46, 5484-5493 (2005).

DOI: $10.1016 /$ j.polymer.2005.05.031

[4] Kurisawa M., Yokoyama M., Okano T.: Gene expression control by temperature with thermo-responsive polymeric gene carriers. Journal of Control Release, 69, 127-137 (2000).

DOI: 10.1016/S0168-3659(00)00297-2

[5] Hu B., Fuchs A., Huseyin S., Gordaninejad F., Evrensel C.: Atom transfer radical polymerized MR fluids. Polymer, 47, 7653-7663 (2006).

DOI: $10.1016 /$ j.polymer.2006.08.069

[6] Ayres N., Boyes S. G., Brittain W. J.: Stimuli-responsive polyelectrolyte polymer brushes prepared via atom-transfer radical polymerization. Langmuir, 23, 182-189 (2007). DOI: $10.1021 / 1 \mathrm{a} 0615261$

[7] Su X., Feng Y., Wang B., Lu Z., Wei L.: Oligomeric cationic surfactants prepared from surfmers via ATRP: Synthesis and surface activities. Colloid and Polymer Science, 289, 101-110 (2011). DOI: $10.1007 / \mathrm{S} 00396-010-2331-6$

[8] Gao Y., Li H., Wang X.: Synthesis and characterization of syndiotactic polystyrene-graft-poly(glycidyl methacrylate) copolymer by atom transfer radical polymerization. European Polymer Journal, 43, 1258 1266 (2007).

DOI: $10.1016 /$ j.eurpolymj.2007.01.045

[9] Hansen N. M. L., Jankova K., Hvilsted S.: Fluoropolymer materials and architectures prepared by controlled radical polymerizations. European Polymer Journal, 43, 255-672 (2007). DOI: $10.1016 /$ j.eurpolymj.2006.11.016

[10] Jakubowski W., Matyjaszewski K.: New segmented copolymers by combination of atom transfer radical polymerization and ring opening polymerization. Macromolecular Symposia, 240, 213-223 (2006). DOI: $10.1002 /$ masy.200650826

[11] Lu J-M., Xu Q-F., Yuan X., Xia X-W., Zhai J-X., Wang L-H.: Synthesis, characterization, and fluorescence of end-functionalized polystyrene initiated by 4-chloromethyl benzoic acid and ethyl 4-chloromethyl benzenecarboxylate via ATRP. Journal of Applied Polymer Science, 104, 75-80 (2007).

DOI: $10.1002 /$ app. 25516

[12] Amin A., Sobh R., Ayoub M. M. H.: Three arm star homo- and block co-polymers via atom transfer radical polymerization. Journal of Macromolecular Science Part A: Pure and applied Chemistry, 43, 667-677 (2006).

DOI: $\underline{10.1080 / 10601320600602415}$ 
[13] Zhang X., Ai C., Ma J., Xu J., Yang S.: Synthesis of zwitterionic shell cross-linked micelles with $\mathrm{pH}$ dependent hydrophilicity. Journal of Colloid and Interface Science, 356, 24-30 (2011).

DOI: 10.1016/j.jcis.2010.12.041

[14] Dayananda K., Pi B. S., Kim B. S., Park T. G., Lee D. S.: Synthesis and characterization of $\mathrm{pH} /$ temperaturesensitive block copolymers via atom transfer radical polymerization. Polymer, 48, 758-762 (2007).

DOI: $10.1016 /$ j.polymer.2006.11.040

[15] Skrabania K., Kristen J., Laschewsky A., Akdemir Ö., Hoth A., Lutz J-F.: Design, synthesis, and aqueous aggregation behavior of nonionic single and multiple thermoresponsive polymers. Langmuir, 23, 84-93 (2007). DOI: $10.1021 / \mathrm{la} 061509 \mathrm{w}$

[16] Li Y., Lu G.: ARGET ATRP of methyl methacrylate with 2-(8-heptadecenyl)-4,5-dihydro-1H-imidazole-1ethylamine (OLC) as both ligand and reducing agent in the presence of air. Colloid and Polymer Science, 288, 1495-1500 (2010).

DOI: $10.1007 / \mathrm{s} 00396-010-2285-8$

[17] Chen J., Xiang J., Cai Z., Yong H., Wang H., Zhang L., Luo W., Min H.: Synthesis of hydrophobic polymer brushes on silica nanoparticles via the combination of surface-initiated ATRP, ROP and click chemistry. Journal of Macromolecular Science Part A: Pure and Applied Chemistry, 47, 655-662 (2010).

DOI: $10.1080 / 10601325.2010 .483357$

[18] Oliveira J. M., Salgado A. J., Sousa N., Mano J. F., Reis R. L.: Dendrimers and derivatives as a potential therapeutic tool in regenerative medicine strategies $-\mathrm{A}$ review. Progress in Polymer Science, 35, 1163-1194 (2010). DOI: 10.1016/j.progpolymsci.2010.04.006

[19] Yokoyama R., Suzuki S., Shirai K., Yamauchi T., Tsubokawa N., Tsuchimochi M.: Preparation and properties of biocompatible polymer-grafted silica nanoparticle. European Polymer Journal, 42, 3221-3229 (2006). DOI: 10.1016/j.eurpolymj.2006.08.015

[20] Wang J-S., Matyjaszewski K.: Controlled/‘living’ radical polymerization. Halogen atom transfer radical polymerization promoted by a $\mathrm{Cu}(\mathrm{I}) / \mathrm{Cu}(\mathrm{II})$ redox process. Macromolecules, 28, 7901-7910 (1995). DOI: $10.1021 / \mathrm{ma} 00127 \mathrm{a} 042$

[21] Matyjaszewski K., Patten T. E., Xia J. H.: Controlled/ 'living' radical polymerization. Kinetics of the homogeneous atom transfer radical polymerization of styrene. Journal of American Chemical Society, 119, 674-680 (1997). DOI: $10.1021 /$ ja963361g
[22] Braunecker W., Matyjaszewski K.: Controlled/‘living’ radical polymerization: Features, developments, and perspectives. Progress in Polymer Science, 32, 93-146 (2007).

DOI: 10.1016/j.progpolymsci.2006.11.002

[23] Grimaud T., Matyjaszewski K.: Controlled/‘living’ radical polymerization of methyl methacrylate by atom transfer radical polymerization. Macromolecules, 30, 2216-2218 (1997).

DOI: $10.1021 / \mathrm{ma961796i}$

[24] Rutnakornpituk M., Puangsin N., Theamdee P., Rutnakornpituk B., Wichai U.: Poly(acrylic acid)-grafted magnetic nanoparticle for conjugation with folic acid. Polymer, 52, 987-995 (2011). DOI: $10.1016 /$ j.polymer.2010.12.059

[25] Li D., He Q., Cui Y., Wang K., Zhang X., Li J.: Thermosensitive copolymer networks modify gold nanoparticles for nanocomposite entrapment. Chemistry-A European Journal, 13, 2224-2229 (2007).

DOI: $10.1002 /$ chem.200600839

[26] Uegaki H., Kotani Y., Kamigaito M., Sawamoto M.: Nickel-mediated living radical polymerization of methyl methacrylate. Macromolecules, 30, 2249-2253 (1997). DOI: $10.1021 / \mathrm{ma961367k}$

[27] Oh J. K., Bencherif S. A., Matyjaszewski K.: Atom transfer radical polymerization in inverse miniemulsion: A versatile route toward preparation and functionalization of microgels/nanogels for targeted drug delivery applications. Polymer, 50, 4407-4423 (2009). DOI: $10.1016 /$ j.polymer.2009.06.045

[28] Ajioka N., Yokoyama A., Yokozawa T.: Synthesis of well-defined rod-coil diblock copolymer of aromatic polyether and polyacrylonitrile by chain-growth condensation polymerization and atom transfer radical polymerization. Macromolecular Rapid Communication, 29, 665-671 (2008).

DOI: $10.1002 /$ marc. 200700862

[29] Huang Z., Zhang Y., Li H., Liu Y.: A novel immobilized cobalt(II)/copper(II) bimetallic catalyst for atom transfer radical polymerization (ATRP) of methyl methacrylate. Applied Catalysis A: General, 332, 192199 (2007).

DOI: $10.1016 /$ j.apcata.2007.07.040

[30] Tang E., Dong S.: Preparation of styrene polymer/ZnO nanocomposite latex via miniemulsion polymerization and its antibacterial property. Colloid and Polymer Science, 287, 1025-1032 (2009). DOI: $10.1007 / \mathrm{s} 00396-009-2057-5$

[31] Bajpai A. K., Shukla S. K., Bhanu S., Kankane S.: Responsive polymers in controlled drug delivery. Progress in Polymer Science, 33, 1088-1118 (2008). DOI: 10.1016/j.progpolymsci.2008.07.005 
[32] Qiu J., Gaynor S. G., Matyjaszewski K.: Emulsion polymerization of $n$-butyl methacrylate by reverse atom transfer radical polymerization. Macromolecules, 32, 2872-2875 (1999).

DOI: $10.1021 / \mathrm{ma} 981695 \mathrm{f}$

[33] Coca S., Jasieczek C. B., Beers K. L., Matyjaszewski K.: Polymerization of acrylates by atom transfer radical polymerization. Homopolymerization of 2-hydroxyethyl acrylate. Journal of Polymer Science Part A: Polymer Chemistry, 36, 1417-1424 (1998).

DOI: $10.1002 /($ SICI)1099-0518(19980715)36:9<1417 $\because$ AID-POLA9 $>3.0 . \mathrm{CO} ; 2-\mathrm{P}$
[34] Pyun J., Jia S., Kowalewski T., Patterson G. D., Matyjaszewski K.: Synthesis and characterization of organic/ inorganic hybrid nanoparticles: Kinetics of surfaceinitiated atom transfer radical polymerization and morphology of hybrid nanoparticle ultrathin films. Macromolecules, 36, 5094-5104 (2003).

DOI: $10.1021 / \mathrm{ma} 034188 \mathrm{t}$

[35] Qiu J., Charleux B., Matyjaszewski K.: Controlled/living radical polymerization in aqueous media: Homogeneous and heterogeneous systems. Progress in Polymer Science, 26, 2083-2134 (2001). DOI: $10.1016 / \mathrm{S} 0079-6700(01) 00033-8$

[36] Asua J. M.: Miniemulsion polymerization. Progress in Polymer Science, 27, 1283-1346 (2002).

DOI: $10.1016 / \mathrm{S} 0079-6700(02) 00010-2$ 